\title{
Choque de oferta, indexação e política monetária: breves considerações sobre a aceleração inflacionária recente ${ }^{\dagger}$
}

\author{
André de Melo Modenesi* \\ Fernando Ferrari Filho*
}

\begin{abstract}
RESUMO - O artigo analisa a aceleração recente do IPCA, procurando mostrar que ela não se refere, genuinamente, a um fenômeno de demanda. As pressões (conjunturais) de custos e o componente (estrutural) inercial têm-se mostrado extremamente relevantes na dinâmica dos preços. Em ambos os casos, o uso da política monetária (PM) é um mero paliativo: atenua os efeitos, mas não as causas da inflação. A PM, na melhor das hipóteses, é pouco eficaz para combater esses dois elementos. Ademais, argumenta-se que o elevado sacrifício imposto pela PM torna urgente a busca de mecanismos alternativos, entre os quais destacamos: i) política tributária contracíclica, visando neutralizar o choque de preços das commodities; ii) política agrícola alicerçada em estoques reguladores para reduzir a volatilidade dos preços dos alimentos; e iii) nova rodada de desindexação da economia.
\end{abstract}

Palavras-chave: Indexação. Inflação. Choque de oferta. Mecanismo de transmissão da política monetária.

\section{INTRODUÇÃO}

Desde o início de 2011, o Índice de Preços ao Consumidor Amplo (IPCA) tem se acelerado mês após mês. Nos últimos 12 meses encerrados em julho, a inflação acumulou alta de 6,9\% (Tabela 1). Trata-se de valor muito acima do centro do intervalo de flutuação perseguido pelo Banco Central do Brasil (BCB), 4,5\% a.a. - superando, inclusive, o teto de 6,5\%.

Em linha com o regime de metas para a inflação (RMI), o Comitê de Política Monetária (Copom) do BCB iniciou novo ciclo de alta da taxa básica de juros (Selic), visando reverter a tendência de elevação dos preços: entre janeiro e agosto, a Selic saltou de 10,75\% para 12,5\% a.a. Trata-se de uma das maiores taxas de juros reais do mundo, superior a 5,0\%. Uma verdadeira aberração, principalmente quando se leva em conta que as taxas de juros internacionais têm sido mantidas próximas a zero.

\footnotetext{
† Artigo finalizado em 31/08/2011. Os autores agradecem os comentários de Noberto M. Martins, Rui L. Modenesi e Tarciso Gouveia, isentando-os, como de praxe, de eventuais erros e omissões.

* Doutor em Economia pela Universidade Federal do Rio de Janeiro. É professor adjunto do Instituto de Economia da Universidade Federal do Rio de Janeiro, pesquisador do CNPq e diretor da Associação Keynesiana Brasileira. Endereço eletrônico: amodenesi@gmail.com.

** Doutor em Economia pela Universidade de São Paulo. É professor titular da Universidade Federal do Rio Grande do Sul, pesquisador do CNPq e ex-presidente da Associação Keynesiana Brasileira. Endereço eletrônico: ferrari@ufrgs.br.
} 
A despeito da elevação da Selic, a inflação resiste em querer baixar. Por quê? Por uma razão muito simples: a inflação brasileira não é, genuinamente, um fenômeno de demanda ${ }^{1}$. Antes pelo contrário, a dinâmica inflacionária é, em larga medida, explicada por dois componentes que guardam pouca relação com o nível de atividade econômica doméstica.

O primeiro tem caráter mais conjuntural e resulta de um choque internacional dos preços das commodities. O segundo tem caráter estrutural - com origens históricas - e se refere ao alto grau de inércia inflacionária. Em suma, as pressões (conjunturais) de custos e o componente inercial explicam boa parte da dinâmica da atual inflação. O problema é que a política monetária (PM), na melhor das hipóteses, é pouco eficaz para combater esses dois elementos que estão por trás da recente aceleração inflacionária. A elevação da Selic, além de pouco eficaz, tem imposto um elevado sacrifício à economia brasileira, o que torna urgente a busca de instrumentos alternativos.

\section{CHOQUE DE COMMODITIES E INFLAÇÃO IMPORTADA DO EXTERIOR}

Em termos conjunturais, destaca-se a ocorrência de intenso choque negativo de oferta, medido por alta expressiva e generalizada dos preços internacionais das commodities. Nos últimos 12 meses, segundo cálculos do IPEA (2011), o índice de preços das commodities acumulou elevação de 34,7\%, com destaque para os seguintes itens: petróleo e derivados (42,15\%); frutas, grãos e oleaginosas (41,86\%); minerais (19,35\%); matérias-primas (13,62\%); e carnes $(12,08 \%)$.

TABELA 1 - IPCA (ACUMULADO), AGOSTO/2010 - JULHO/2011

\begin{tabular}{|c|c|c|c|c|}
\hline \multirow{2}{*}{ Grupos } & \multirow{2}{*}{ Variação (\%) } & \multirow{2}{*}{ Peso $(\%)$} & \multicolumn{2}{|c|}{ Participação no IPCA } \\
\hline & & & Absoluta (pp.) & Relativa (\%) \\
\hline Alimentação e Bebidas & 9,36 & 23,30 & 2,18 & 31,55 \\
\hline Habitação & 6,32 & 13,20 & 0,83 & 12,01 \\
\hline Artigos de Residência & 1,32 & 3,98 & 0,05 & 0,72 \\
\hline Vestuário & 8,81 & 6,88 & 0,61 & 8,83 \\
\hline Transporte & 5,68 & 18,76 & 1,06 & 15,34 \\
\hline Desp. Pessoais & 8,27 & 10,47 & 0,86 & 12,45 \\
\hline Comunicação & 1,66 & 5,34 & 0,09 & 1,30 \\
\hline Educação & 8,27 & 7,32 & 0,60 & 8,68 \\
\hline Saúde e Cuidados Pessoais & 5,91 & 10,75 & 0,63 & 9,12 \\
\hline Total & - & 100 & 6,91 & 100 \\
\hline
\end{tabular}

FONTE: IBGE.

1 De forma geral, as pressões de demanda explicam pouco o comportamento dos preços no Brasil. Por exemplo, Summa e Macrini (2011) mostram que "o hiato do produto (e do desemprego) não apresenta relação sistemática com a inflação [...] a inflação importada em R e a variação da Selic apresentam relação mais clara com a inflação, evidenciando um forte componente de pressão de custos". Resultados similares também foram encontrados por Summa (2010), Araújo e Modenesi (2010a, 2010b), Summa e Santolin (2011), Braga (2011) e Vianna et al. (2010), entre outros. 
Essa inflação importada do exterior tem contaminado fortemente o IPCA, refletindo-se em alta expressiva do grupo "Alimentação e Bebidas" (9,36\%), que representa cerca de um quarto da composição do índice. Foi o item que mais contribuiu para a elevação do IPCA, respondendo por 2,18 pp. (cerca de 32,0\%) da variação acumulada no período (Tabela 1).

Cabe notar que os mercados de commodities têm sido influenciados pelo processo de globalização financeira, entendida como financeirização da riqueza. Assim, tem-se observado uma dinâmica fortemente especulativa na formação dos preços das commodities - que se financeirizaram, tornando-se verdadeiros ativos financeiros.

Nesse sentido, a recente alta dos preços das commodities não reflete, unicamente, fatores estruturais - ou os fundamentos econômicos, como a interação entre oferta e demanda. Antes pelo contrário, há um componente conjuntural essencialmente especulativo impulsionado pela flexibilização coordenada e sem precedentes da PM por parte dos principais bancos centrais do mundo (Federal Reserve Bank, Banco Central Europeu e Banco do Japão), verificada nos últimos $\operatorname{anos}^{2}$.

A propósito, cabe notar que Keynes (1976) - em seu plano de reestruturação do sistema monetário internacional - ressaltou a necessidade de se estabilizar os preços de 62 commodities como condição fundamental para evitar pressões inflacionárias e deflacionárias na economia mundial. Como apontado por Keynes, caso isso não ocorresse, as taxas de câmbio se tornariam mais voláteis. Da mesma forma, a moeda de reserva internacional teria sua estabilidade comprometida, bem como se criaria espaço para o uso de políticas protecionistas e/ou das chamadas desvalorizações competitivas da taxa de câmbio (beggar thy neighbour).

Em suma, é preciso adotar medidas que coíbam movimentos especulativos nos mercados de commodities. Isso contribuiria largamente para uma maior estabilidade do sistema monetário internacional, reduzindo-se a volatilidade cambial e as pressões inflacionárias globais. Atuar na raiz do problema seria a melhor forma de lidar com o atual choque de oferta.

O uso da PM para conter a inflação com origem no lado da oferta (custos) não é o mais apropriado, mesmo em condições normais. Nesse caso, atua-se meramente sobre os sintomas e não sobre as causas da inflação (DAVIDSON, 1978). A PM somente conteria os efeitos secundários da inflação importada: ao retrair a atividade, coibiria o repasse dos preços externos para os preços domésticos. Além disso, ao se restringir a PM, amplia-se o impacto recessivo de uma elevação dos custos de produção.

2 É verdade que a ascensão econômica de alguns países emergentes, com destaque para a China, explica uma mudança de preços relativos em benefício das commodities. Trata-se de um componente de caráter mais estrutural que responde por parte da alta dos referidos preços nos últimos anos. No entanto, a alta expressiva desses preços não pode ser atribuída unicamente a tal fato. 
Isso é verdade, mesmo na hipótese de que o mecanismo de transmissão da PM funcione perfeitamente. Entretanto, no caso brasileiro, esse mecanismo não tem funcionado de forma adequada $^{3}$. Isso explica a persistente coexistência de taxas reais de juros anomalamente altas com níveis relativamente elevados de inflação. De fato, há um conjunto amplo de evidências de que há falhas na transmissão da PM (MODENESI, 2010). A inflação tem-se mostrado pouco sensível ao nível de atividade econômica: é preciso uma retração de grandes proporções para se obter uma queda relativamente pequena da inflação. Por isso, o BCB não tem sido capaz de trazer o IPCA para menos de 4,5\% a.a. - apesar das altas taxas de juros.

Como mostrado por Araújo e Modenesi (2010a), é baixa a sensibilidade da inflação à taxa de juros. Uma elevação da Selic tem reduzido impacto deflacionário. Assim, o BCB precisaria mantê-la em níveis demasiadamente elevados para que as metas para a inflação sejam minimamente cumpridas. Consequentemente, o ganho de bem-estar - medido por uma redução da inflação -, decorrente de uma elevação da taxa de juros, é pequeno. A existência de problemas no mecanismo de transmissão amplia ainda mais o sacrifício imposto pela PM à economia brasileira. Entre os custos de uma elevação da Selic se destacam:

1. Baixo dinamismo econômico - o que nos confere a menor taxa média de crescimento entre os países emergentes. A elevação dos juros impacta a preferência pela liquidez dos agentes econômicos que, por sua vez, acabam postergando suas decisões de consumo e de investimento.

2. Sobrevalorização do real - o elevado diferencial entre a Selic (12,5\%) e as taxas de juros internacionais (próximas a zero) torna o Brasil o principal destino das operações de arbitragem (carry trade). A valorização cambial é indesejável, pois reduz a competitividade das exportações o que, por sua vez, deteriora o saldo total do balanço de pagamentos e aumenta a fragilidade externa da economia. Ressalte-se que o câmbio tem sido o principal canal de transmissão da PM.

3. Elevada despesa com o pagamento de juros da dívida pública (entre 5,0\% e 7,0\%

3 Entre os fatores que comprometem o funcionamento do mecanismo de transmissão da PM no Brasil, destaca-se a existência das Letras Financeiras do Tesouro (LFT), título pós-fixado (sem risco de juros) indexado à Selic. Sua alta participação no estoque da dívida pública, por sua vez, reduz a eficácia da PM, na medida em que: desfavorece a existência de uma curva de rendimentos para prazos de maturação suficientemente longos; e gera um efeito riqueza financeira às avessas (um aumento da taxa Selic cria um incremento de renda que tende a ampliar a demanda agregada, contribuindo para a alta dos preços). Outro fator a prejudicar o funcionamento desse mecanismo no Brasil é a elevada participação dos preços administrados no IPCA (cerca de 30,0\%), que não são formados pela interação entre oferta e demanda, tornando-se praticamente insensíveis à taxa de juros. Para maiores detalhes, ver Modenesi e Modenesi (2011). 
do PIB), comprometendo o esforço fiscal do Governo para equilibrar suas contas - cerca de 1/3 do total da dívida é indexado à Selic.

4. A existência de um canal de custos na condução da PM. Admitindo-se que os preços são determinados por uma regra de mark-up sobre os custos de produção, um aumento dos juros eleva os custos que, por sua vez, tendem a ser repassados para os preços. Nesse caso, o impacto inflacionário do aumento dos custos de produção pode anular o efeito depressivo sobre os preços resultante de uma contração monetária ${ }^{4}$.

Resumindo, a origem da recente aceleração inflacionária não se encontra em um superaquecimento econômico - o que poderia justificar um aperto monetário. Para controlar a inflação, do ponto de vista mais conjuntural, é necessário neutralizar a inflação importada. Nas condições atuais, o uso da taxa de juros é duplamente indesejável. Primeiro, porque ela não atua sobre o cerne do problema. Segundo, porque seu uso tem se mostrado extremante custoso ${ }^{5}$.

Além disso, com a taxa de câmbio em torno de R $\$ 1,60 /$ US $\$ 1,00$, seria temerário buscar promover nova rodada de valorização cambial por meio de elevação da Selic - cerne da atual política anti-inflacionária (ARAÚJO; MODENESI, 2010b). O impacto deflacionário dessa estratégia está se esgotando, ao passo que os efeitos deletérios da valorização (desestímulo a produção industrial; primarização da pauta de exportações etc.) estão se acumulando. Ou seja, o atual patamar da taxa de câmbio torna ainda menos aconselhável uma alta da Selic.

O mais indicado seria adotar uma política tributária anticíclica que neutralizasse (ao menos parcialmente) o choque no preço dos alimentos - a exemplo do que já acontece com a alíquota da CIDE que, para compensar o impacto no preço dos combustíveis, tem variado no sentido inverso do preço do petróleo ${ }^{6}$. Isso não somente reduz as pressões inflacionárias como diminui a volatilidade do preço dos combustíveis. Complementarmente, seria importante a adoção de uma política agrícola que estabilizasse o preço dos alimentos - definindo-se pisos e tetos ao produtor de itens estratégicos - por meio do gerenciamento de estoques reguladores.

4 A relevância deste canal (perverso) de transmissão da PM é diretamente proporcional ao grau de concentração dos setores produtivos: quanto mais concentrado, maior o poder de mercado das firmas e, portanto, maior a capacidade de se repassar aumento dos custos de produção para os preços finais. O alto grau de concentração industrial (ou a existência de oligopólios) verificado no país favorece a existência desse canal de custos, comprometendo, ainda mais, a eficácia da PM no combate a inflação.

5 Em último caso, se o BCB insistir em reduzir o nível de atividade econômica, recomenda-se que o faça com o uso de medidas de controle de crédito, menos nocivas para a economia. Elas têm, ao menos, a vantagem de ser menos custosas visto que não impactam a dívida pública, nem estimulam a valorização cambial.

6 Ver, por exemplo, Valor Econômico (2011). 


\section{INDEXAÇÃO E INÉRCIA INFLACIONÁRIA}

O componente estrutural da inflação brasileira refere-se a um elevado grau de inércia inflacionária, decorrente dos mecanismos de indexação que ainda persistem na economia do país. O Plano Real (PR) promoveu uma desindexação apenas parcial da economia. Por um lado, parcela relevante de bens e serviços continua tendo seus preços atrelados à inflação passada. Além disso, nada foi feito em relação aos ativos financeiros, que também permanecem indexados. Trata-se de uma herança do período de alta inflação, que se mantém intocada dezessete anos após a estabilização dos preços.

As origens do sistema de indexação de preços remontam à reforma monetária de 1964-5, no âmbito do PAEG do presidente Castello Branco. No início dos anos 1960, havia a chamada ficção da moeda estável: a coexistência de altas taxas de inflação (em 1964, os índices de preços acumulavam altas ao redor de 100,0\%) com a Lei da Usura (limitava os juros em $12,0 \%$ a.a.). Isso inibia a demanda voluntária por títulos públicos (que apresentavam rendimento real negativo), comprometendo-se, assim, o financiamento não inflacionário do déficit.

A brilhante solução deu-se na forma de um título público indexado, as Obrigações Reajustáveis do Tesouro Nacional (ORTN), que restaurou a demanda por títulos públicos. No entanto, aquilo que, no curto prazo, parecia ser uma ótima solução transformou-se em verdadeiro "tiro no pé". As ORTN representaram o pecado original da ampla disseminação de mecanismos (formais e informais) de indexação, que distinguia a economia brasileira no final dos 1970: era uma economia plenamente indexada.

Se, por um lado, a indexação assegurou uma convivência pacífica com a inflação, por outro lado, dificultou a eliminação da mesma. A razão é bem conhecida dos brasileiros: o processo inflacionário tornou-se inercial, como ficou claro a partir dos anos 1980. A inflação passada projetava-se para o futuro, criando-se um movimento de alta dos preços autônomo em relação ao lado real da economia. Isto é, a inflação inercial não resultava de choques de demanda nem de oferta.

Consequentemente, a PM (que atua sobre a demanda) se tornou pouco eficaz. O mesmo ocorre com as medidas de combate à inflação pelo lado dos custos, como as chamadas políticas de renda. No limite, o gestor de política econômica torna-se incapaz de debelar a inflação com os instrumentos tradicionais.

A interrupção do processo de alta inflação crônica foi obtida com sucesso pela reforma monetária do PR. A proibição de indexação por prazos inferiores a um ano e a criação da URV reduziram fortemente o peso do componente inercial da inflação, recuperando-se, substancialmente, a eficácia dos instrumentos tradicionais de estabilização. Assim, foi vencida a 
batalha contra a alta inflação crônica.

Mas a guerra da estabilização ainda não está ganha. Ainda falta vencer a batalha da erradicação do piso inflacionário, que marca a economia nos 17 anos pós-PR: o IPCA se manteve abaixo de 5,0\% a.a. em apenas quatro ocasiões e sua média foi superior a 7,0\%, a despeito das doses cavalares da Selic ${ }^{7}$.

Apesar do grande avanço, a desindexação do PR foi incompleta e os mecanismos de indexação ainda permeiam variados setores da economia. Quanto aos preços, destacam-se os aluguéis (indexados ao IGP-M), as tarifas de energia elétrica (parcialmente atrelada ao IGP-M) e de telefonia (indexada a um índice setorial, IST, também composto pelo IGP-M) e o salário mínimo (que passou a ser indexado ao IPCA e ao crescimento do PIB). São preços chave da economia, insumos de larga utilização, cuja indexação amplia o componente inercial da inflação.

No lado financeiro, nada foi feito: o PR manteve intocadas as anacrônicas instituições monetárias e financeiras do período de alta inflação. É preciso reformá-las, tornando-as compatíveis com a atual condição de estabilidade de preços. A existência de ativos financeiros altamente líquidos (muitos com liquidez diária) e pós-fixados (indexados ao CDI) é uma anormalidade. Não há nada similar em economias com preços minimamente estáveis, como o Brasil pós-PR. O mesmo vale para as LFT: um ativo singular, com alta liquidez e rentabilidade e sem risco de taxa de juros, que acaba distorcendo a curva de rendimentos - que tende a tornar-se mais curta e inclinada - e inibindo o financiamento de mais longo prazo.

A indexação compromete, portanto, dois elementos-chave de uma estratégia de desenvolvimento econômico, em linha com o chamado Novo Desenvolvimentismo. Primeiro, contribui para reduzir a eficácia da PM, demandando taxas de juros relativamente altas, dadas as metas para a inflação, com efeitos deletérios sobre a atividade econômica, o câmbio e as contas públicas. Segundo, limita o financiamento de longo prazo, inibindo investimentos estratégicos (por exemplo, em infraestrutura) e, assim, perpetuando os obstáculos ao crescimento sustentável. Não é à toa que no período pós-PR o PIB cresceu em média 3,3\% a.a., numa trajetória de stop-and-go.

A dificuldade é que há um dilema. Por um lado, a eliminação voluntária (por parte dos agentes privados) dos mecanismos de indexação pressupõe um ambiente de estabilidade bem consolidado - do contrário, os brasileiros, que têm o DNA da inflação no sangue, vão continuar buscando proteção. Por outro lado, a consolidação de um ambiente de estabilidade requer a desindexação. A PM não é capaz de solucionar esse problema. O único agente capaz de resolver esse dilema é o Estado: é preciso promover uma nova rodada de desindexação, que elimine os

7 Excluindo-se o período julho-dezembro/1994, quando a inflação acumulou 26,4\%. 
entulhos remanescentes do período de alta inflação crônica. Enfim, a guerra da estabilização ainda está para ser vencida, dezessete anos após o PR.

\section{CONSIDERAÇÕES FINAIS}

A inflação brasileira não é, genuinamente, um fenômeno de demanda. Antes pelo contrário, as pressões (conjunturais) de custos e o componente (estrutural) inercial têm-se mostrado extremamente relevantes na dinâmica inflacionária. Em ambos os casos, o uso da PM é um mero paliativo: atenua os efeitos, mas não as causas da inflação. Em suma, a PM, na melhor das hipóteses, é pouco eficaz para combater esses dois elementos que explicam boa parte da recente alta da inflação.

Se continuarmos insistindo no uso da Selic como o instrumento primordial de combate ao problema inflacionário, seguiremos batendo recordes mundiais em termos de taxas de juros (reais), sem que a inflação se reduza de forma mais contundente.

O elevado sacrifício imposto pela PM torna urgente a busca de mecanismos alternativos. A Selic não deve ser o único instrumento de combate à inflação, principalmente quando não há, predominantemente, pressão inflacionária pelo lado da demanda. Nesse caso, não há uma regra simples; inflações com causas distintas devem ser combatidas com diferentes instrumentos, entre os quais destacamos:

1. Uma política tributária contracíclica que neutralize o choque de preços das commodities.

2. Uma política agrícola que, baseada em estoques reguladores, reduza a volatilidade dos preços dos alimentos.

3. Uma nova rodada de desindexação - tanto dos preços quanto dos ativos financeiros - promovida pelo Governo.

\section{REFERÊNCIAS}

ARAÚJO, E.; MODENESI, A. M. Custos e benefícios do controle inflacionário no Brasil (2000-2008): uma análise empírica do mecanismo de transmissão da política monetária com base em um modelo VAR. In: ENCONTRO NACIONAL DE ECONOMIA (ANPEC), 28., 2010a, Salvador. Anais... CD-ROM.

ARAÚJO, E.; MODENESI, A. M. A importância do setor externo na evolução do IPCA (1999-2010): uma análise com base em um modelo SVAR. In: ENCONTRO NACIONAL DE ECONOMIA (ANPEC), 28., 2010b, Salvador. Anais... CD-ROM. 
BRAGA, J. M. A infação brasileira na decada de 2000 e a importância de políticas não monetárias de controle. Seminários Dimac (IPEA), n. 374, 2011.

DAVIDSON, P. Money and the real world. London: Macmillan, 1978.

IPEA. Disponível em: <http://www.ipea.gov.br>. Acesso em: 30/8/2011.

KEYNES, J. M. A treatise on money. New York: MAS Press, 1976. v. 2.

MODENESI, A. M. Política monetária no Brasil pós-plano real (1995-2008): um breve retrospecto. Economia \& Tecnologia, Curitiba, v. 21, p. 21-30, abr./jun. 2010.

MODENESI, A. M.; MODENESI, R. L. Quinze anos de rigidez monetária no Brasil: uma agenda de pesquisa. Revista de Economia Política, São Paulo, 2011. No prelo.

SUMMA, R. Uma avaliação crítica das estimativas da curva de Phillips no Brasil. In: ENCONTRO NACIONAL DE ECONOMIA POLÍTICA, 15., 2010, São Luis. Anais... CD-ROM.

SUMMA, R.; MACRINI, J. L. Estimando a curva de Phillips brasileira no período do sistema de metas de inflação por redes neurais. In: ENCONTRO DE ECONOMIA DA REGIÃO SUL, 14., 2011, Florianópolis. Anais... CD-ROM.

SUMMA, R.; SANTOLIN, R. Um modelo alternativo ao novo consenso para economia aberta: evidências para a economia brasileira no período 2000 - 2010. In: ENCONTRO NACIONAL DA ASSOCIAÇÃO KEYNESIANA BRASILEIRA, 4., 2011, Rio de Janeiro. Anais... CDROM.

VALOR ECONÔMICO. Importaçao de gasolina vai custar R \$ 200 milhões, calcula mercado. Valor Econômico, p. A-3, ago. 2011.

VIANNA, S. W.; BRUNO, M. A. P.; MODENESI, A. M. (Org.). Macroeconomia para o desenvolvimento: crescimento emprego e estabilidade. Rio de Janeiro: IPEA, 2010. 
